\title{
Flight Simulation Training Device Operating Standards for MPL Training Programs in South Korea
}

\author{
Jang Ryong Lee", Moonjin Kwon", Hanjoon Kwon ${ }^{\text {mome }}$
}

\begin{abstract}
The Multi-crew Pilot License (MPL) is a new pilot qualification introduced by ICAO to train co-pilots for transport aircraft based on efficient and stable competency to respond to changes in the operating environment and technology. ICAO and the European Union Aviation Safety Agency (EASA) require a minimum flight of 240 hours for MPL qualification training, and allow the use of flight simulation training devices (FSTDs) for most of the training, specifying the performance requirements for FSTDs. As South Korea is also preparing for the operation of the MPL training program, it is essential to establish the operating standards for FSTDs required for MPL training. This study aims to identify the international standards for FSTDs related to MPL training, and to compare them with the current operating standards for FSTDs in South Korea for presenting a standard (draft) that can be used when introducing domestic MPL training programs in the future.
\end{abstract}

Key Words : Multi-crew Pilot License (MPL), Multi-Pilot, Competency, Approved Training Organization (ATO), Flight Simulation Training Device (FSTD)

\section{INTRODUCTION}

The development of the aviation industry has led to technological evolution related to aircraft operation and pilot training. However, since the inefficiency of traditional pilot training as a time-based approach has been continuously pointed out, competency-based training has emerged as a countermeasure [1][2].

Received: 10. Sep. 2021, Accepted: 14. Sep. 2021

* Professor, Department of Aeronautical Science \& Flight Operations, Korea Aerospace University

Corresponding Author E-mail : jrherky@kau.ac.kr Corresponding Author address : Office 524, Main

Buiding, 76 Hanggongdaehak-ro, Deogyanggu, Goyang, Gyeongi-do, Korea

** Ph.D. Candidate, Department of Aviation Management, Korea Aerospace University

*** Graduate Student for MS, Department of Aviation Management, Korea Aerospace University
In the traditional pilot training system, a small aircraft operated by one person is used for flight training for at least 250 to 1,000 hours. Nevertheless, the aircraft used in the air transportation business is operated by two or more pilots based on the multi-crew concept, leaving new pilots entering the civil aviation sector lacking in education and training on the aircraft for the air transportation business until they acquire pilot qualifications [3].

In order to improve the limitations of this traditional pilot training system and to enable more efficient and effective pilot training, the International Civil Aviation Organization (ICAO) introduced the Multi-crew Pilot License (MPL) as a new international qualification for pilots in 2006 [4].

As ICAO has also emphasized that flight simulation training devices (FSTDs) are actively 
used for the MPL qualification training programs [5], a discussion on the operating standards of FSTDs is required for operating the MPL training program in the future.

Therefore, this study intends to identify the standards for FSTDs by grade presented by international civil aviation organizations such as ICAO and the European Union Aviation Safety Agency (EASA), and to compare them with the current standards in South Korea, with the aim of proposing operating standards for FSTDs that need to be reflected in the MPL training program in South Korea.

\section{BODY}

\subsection{FSTD Operating Standards for MPL Training Programs by ICAO}

The ICAO operating standards for general FSTDs are stipulated in the Manual of Criteria for the Qualification of Flight Simulation Training Devices (ICAO Doc 9625), which classifies FSTDs into seven different categories from Type I to Type VII.

Furthermore, ICAO has divided the FSTD into $\mathrm{T}$ or TP according to the purpose of use, and into $S, R, G$, and $N$ according to the reliability level. $\mathrm{T}$ (Training) indicates a device suitable for performing specific education and training to issue a license and a rating qualification, but not for training-to-proficiency, whereas TP (Training-to-Proficiency) indicates a device suitable for education and training to ensure proficiency from the start to completion of specific training as well as to issue a license and a rating qualification.

As for the reliability level, S (Specific) indicates the highest level, followed by R (Representative) and $G$ (Generic), and $N$ (None) indicates that reliability is not required [G].

On the other hand, ICAO Annex 1 and Doc 9868 state that there are four types of FSTDs, from Type I to Type IV, that can be used in training for MPL qualification, which corresponds to each of the four stages of the MPL training program, from Phase 1 (Core flying skills) to Phase 4 (Advanced). However, there are some vague aspects as different names are used in ICAO Doc 9625, which specifies the general flight training system standards, and Doc 9868, which lists the FSTDs used for the MPL training program. In terms of performance level, Type I through Type IV devices in Doc 9868 correspond to Type I, IV, VI, and VII devices in Doc 9625, respectively [7].

Type I FSTDs used in Phase 1 (Core flying skills), the first stage of the MPL training program, refer to devices with a level higher than a desktop computer equipped with peripherals such as a throttle, sidestick controller or FMS keypad. In Phase 2 (Basic), the second stage of the MPL training program, Type II FSTDs that can simulate the performance of a turbine engine aircraft are used, and Phase 3 (Intermediate) requires Type III FSTDs that can simulate the performance of a turbine-powered multi-engine aircraft, equipped with an enhanced daylight visual system, operated by two pilots. In Phase 4 (Advanced), the last stage of the MPL training program, the highest-level FSTDs with full motion are used [8].

\subsection{FSTD Operating Standards for MPL Training Programs by EASA}

EASA specifies detailed standards for general FSTDs in the Certification Specifications for Airplane Flight Simulation Training Devices (EASA CS-FSTD), which classifies FSTDs into 10 different categories, including basic instrument training devices (BITDs), flight and navigation procedures trainers (FNPTs), flight training devices (FTDs), and full flight simulators (FFSs) from Levels A to D [9].

In addition, EASA Part-FCL has designated BITD/FNPT I, FNTP II/FNTP MCC, LEVEL B FSS, and LEVEL C/D FFS as FSTDs that can be used for MPL qualification, which is used in the 
process from Phase 1 to Phase 4, respectively [10].

In Phase 1, the first stage of training for MPL qualification, FSTDs including BITD or FNTP I are used. These devices should have performance above the desktop level with appropriate control sensitivity and response speed, and should be equipped with peripherals such as a throttle, sidestick controller, or FMS keypad. In Phase 2, the second stage of training for MPL qualification, FSTDs including FNTP II and multi-crew cooperation (MCC) simulation systems are used, which should be able to simulate the performance of a turbine-powered multi-engine aircraft. Phase 3 requires FSTDs including Level B FFS with ATC simulation, which can simulate the performance of a turbine-powered multiengine aircraft, operated by two pilots, providing a horizontal $180^{\circ}$ and vertical $40^{\circ}$ field of view day and night. In Phase 4 , the last stage of training for MPL qualification, FSTDs including Level C FFS or Level D FFS with ATC simulation, equipped with expanded sound, motion, and vibration functions, are used [11].

\subsection{FSTD Operating Standards and Current Status in South Korea}

In South Korea, FSTDs are largely divided into full flight simulators (FFSs) (Levels 1 to 3 ) and flight training devices (FTDs) (Levels A to D1)).

Detailed requirements for each device are stipulated in the notification of the Ministry of Land, Infrastructure and Transport (Standards for Designation of Flight Simulation Training Devices and Inspection Guidelines) and in the attached table of the notification [12].

According to the notification, FFS is a replica of the inside of the aircraft cockpit, which is defined as a device equipped with all the equipment and computer programs necessary for flight and ground operation, as well as visual and motion devices to simulate the same perfor- mance as in a real aircraft cockpit on the ground and in the air on instruments and visual devices. In Attached Table 6 of the notification (Detailed Requirements for Full Flight Simulators by Level), each sub-item for general equipment, exercise system, and visual system is specified, and the items to be satisfied by class are stipulated. More precise and detailed performance standards such as the characteristic motions of aircraft, noise effects, and meteorological phenomena are required for a higher level [13].

The notification also defines FTDs as devices designed to have a cockpit similar to that of an actual aircraft, simulating each system and performance of the aircraft, such as instruments, machinery, electricity, and electronics, for facilitating the understanding of the aircraft systems and mastery of flight procedures under the conditions of instrument flight. Attached Table 3 of the notification (Detailed Requirements for Flight Training Devices by Level) specified the requirements of which the FTD should equipped with by class according to 22 items including cockpit, lighting, control reaction, and navigation devices. More items are required for a higher level [14].

On the other hand, Attached Table 12 (refer to Table 1 below) of the notification specifies the allowable range for designating FSTDs, stipulating the training items that can be performed with FSTDs by level [15].

\subsection{Comparison of International and Domestic Standards and Analysis of Domestic Operating Status}

In South Korea, the standards of the Federal Aviation Administration (FAA) AC120 are applied mutatis mutandis as a prerequisite to qualification for the level of FSTD [16], but internationally, the operation of FSTDs related to MPL training follows the ICAO and EASA

1) 한국 지침(notification) 원본은 "가" “라"로 명시하고 있으나 영문번역을 위해 "A" to "D”로 표기함(모든 표, 그림에 적용). 
Table 1. FSTDs allowable range of designation

\begin{tabular}{c|l}
\hline Category & \multicolumn{1}{|c}{ Allowable range of designation } \\
\hline $\begin{array}{c}\text { Flight training } \\
\text { devices } \\
\text { levels A to D }\end{array}$ & $\begin{array}{l}\text { (1) Instrument flight and flight } \\
\text { procedure training } \\
\text { aircraft operation procedures } \\
\text { and systems } \\
\text { (3) Instrument flight experience } \\
\text { and examination (with } \\
\text { permission) }\end{array}$ \\
\hline Level 1 FFS & $\begin{array}{l}\text { (1) Range of FTDS } \\
\text { (2) Recent flight experience of } \\
\text { the aircraft concerned }\end{array}$ \\
(3) Night takeoff and landing \\
training
\end{tabular}

standards [17][18].

Therefore, in preparation for the operation of the MPL training program in South Korea, devices of the same level were identified by comparing the current domestic FSTD requirements with the standards for each level of FSTDs presented by ICAO and EASA, and the devices that could be used for MPL qualification training were analyzed for each stage of the training program.

As a result of the analysis, as for the MPL training program of South Korea (refer to Fig. 1 ), it seemed adequate to use at least Level "A" FTDs in Phase 1 (Core flying skills), Level "B" FTDs in Phase 2 (Basic), Level 1 FSSs in Phase 3 (Intermediate), and Level 2 FSSs in Phase 4 (Advanced).

However, according to the operating status

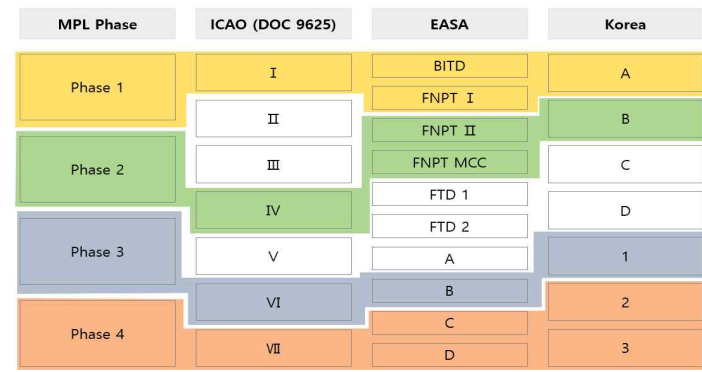

Fig. 1. The FSTDs grade applied to MPL phase

of FSTDs in South Korea (refer to Table 2) published by the Seoul Regional Office of Aviation (SROA) in 2017, 17 out of a total of 23 FTDs were Level "A" devices, and 22 out of a total of 23 FFSs were Level "3" devices [19]. Not only is there a shortage in terms of the overall number of operating units, but also most of the units are of Levels "A" and "B," suggesting difficulties in the operation of the intermediate stages of the MPL training program in the future.

\section{CONCLUSION}

The MPL qualification system is a new qualification system adopted by ICAO in 2006 to foster and provide efficient competency- based training for pilots in a rapidly changing operating environment.

Since the MPL training program for pilots involves a high proportion of training using FSTDs, it is also necessary to set clear standards for the type and performance of FSTDs required for each stage of the MPL training program in South Korea.

This study has revealed that although there are general operating standards for FSTDs in South Korea, most of them are related to traditional pilot training, and that Level "A" FTDs and Level "3" FFSs account for the most proportion of the FSTDs in terms of field operation, with a shortage of FSTDs suitable for the intermediate stages of the MPL training program. 
Therefore, in order to introduce the domestic MPL training program, it seems necessary to establish domestic FSTD standards for the MPL training program by referring to the FSTD standards for MPL training proposed by ICAO and EASA in advance, which are applied overseas, and to procure FSTDs necessary for the intermediate stages of MPL training, centering on potential training organizations for MPL training.

\section{References}

1. Sullivan, R., and Mcintosh, N., "The Competency-Based Approach to Training”, 1996.

2. Harris, R., Guthric, H., Hobart, B., and Lundberg, D., "Competency-Based Education and Training - Between a Rock and a Whirlpool”, 1995.

3. Kim, B. G., "Study for implementing Multi-crew Pilot License(MPL) in Korea”, Master's Degree, Far East University, Eumseong, Souh Korea, 2021 Feb.

4. IATA, "Guidance Material and Best Practices for MPL Implementation”, International Air Transport Association, Montreal, Canada, 2015.

5. ICAO, “Doc 9868, Training”, International Civil Aviation Organization, Montreal, Canada, 2016, p. II-1-1 App 1-1.

6. ICAO, "Doc 9625, Manual of Criteria for the Qualification of Flight Simulation Training Devices”, International Civil Aviation Organization, Montreal, Canada, 2015, p. I-App B-1.

7. ICAO, "Doc 9868, Training”, International Civil Aviation Organization, Montreal, Canada, 2016, p.II-1-1 App 2-1.

8. ICAO, "Annex 1 - Personnel licensing", International Civil Aviation Organization, Montreal, Canada, 2018, p.App 3-2.

9. EASA, "CS-FSTD(A) - Certification Specification for Aeroplane Flight Simulation Training Devices", European Union Aviation Safety Agency, Cologne, Germany, 2012.
10. EASA, "Easy Access Rules for Flight Crew Licensing(Part-FCL)", European Union Aviation Safety Agency, Cologne, Germany, 2020.

11. EASA, "CS-FSTD(A) - Certification Specification for Aeroplane Flight Simulation Training Devices", European Union Aviation Safety Agency, Cologne, Germany, 2012, p.132.

12. MOLIT, "Notification 2018-290, Designation Criteria and Inspection Instructions for Simulated Flight Training Devices", Ministry of Land, Infrastructure, and Transportation, Sejong, South Korea, 2018.

13. MOLIT, "Notification 2018-290 Attached Table 6, The list of full flight simulator requirement", Ministry of Land, Infrastructure, and Transportation, Sejong, South Korea, 2018.

14. MOLIT, "Notification 2018-290 Attached Table 3, The list of detailed requirements for flight training devices", Ministry of Land, Infrastructure, and Transportation, Sejong, South Korea, 2018.

15. MOLIT, "Notification 2018-290 Attached Table 12, The table of training permitted depends on the simulator's level", Ministry of Land, Infrastructure, and Transportation, Sejong, South Korea, 2018.

16. MOLIT, "Notification 2018-290, Designation Criteria and Inspection Instructions for Simulated Flight Training Devices", Ministry of Land, Infrastructure, and Transportation, Sejong, South Korea, 2018.

17. ICAO, "Doc 9868, Training", International Civil Aviation Organization, Montreal, Canada, 2016, p. II-1-1 App 2-1.

18. EASA, "Easy Access Rules for Flight Crew Licensing(Part-FCL)", European Union Aviation Safety Agency, Cologne, Germany, 2020, p.1187.

19. Yoon, S. J., "Development of Civil Simulator and Core Certification Technologies", Final Report, Sejong University, 2018 Dec. 